\title{
A TIPIFICAÇÃO DAS REGRAS E SEUS SENTIDOS DE OBRIGAÇÃo
}

\author{
Mayara Roberta Pablos ${ }^{1}$ \\ Universidade Federal de Santa Catarina (UFSC) \\ (iD) https://orcid.org/0000-0003-2426-7570 \\ E-mail:mayara_pablos@yahoo.com.br
}

\section{RESUMO:}

O presente artigo analisa o conceito de "regras" a partir da concepção de direito apresentada por Herbert Hart em sua obra $O$ Conceito de Direito, mostrando como as regras do direito diferem de outros tipos de regras como as da moralidade, costumeiras, etc. Faremos isso através da distinção entre os sentidos de obrigação que as regras possuem, evidenciando, ao mesmo tempo, o aspecto normativo inerente às regras jurídicas.

PALAVRAS-CHAVE: Regras; Normatividade; Obrigação.

\section{THE TYPIFICATION OF RULES AND THEIR SENSE OF OBLIGATION}

\begin{abstract}
:
This article analyzes the concept of "rules" from the conception of law presented by Herbert Hart in his work The Concept of law, showing how the rules of law differ from others types of rules such as those of morality, customary, and so on. We will do this through the distinction between the sense of obligation that the rules have, highlighting, at the same time, the normative aspect inherent in the legal rules.
\end{abstract}

KEYWORDS: Rules; Normativity; Obligation.

${ }^{1}$ Doutor(a) em Filosofia pela Universidade Federal de Santa Catarina (UFSC), Florianópolis - SC, Brasil.

$\overline{\text { PABLOS, Mayara Roberta. A tipificação das regras e seus sentidos de obrigação. Griot : Revista de Filosofia, Amargosa - BA, v.21 }}$ n.3, p.134-147, outubro, 2021. 


\section{Introdução}

O objetivo deste artigo é apresentar quais são os tipos de regras que compõe ou tangenciam o fenômeno jurídico tal como descrito por Herbert Hart em sua obra $O$ Conceito de Direito. Para isso, será necessário apresentar não somente as regras que fundamentam o direito, mas também, de que forma estas regras diferem dos demais padrões e regras sociais de conduta como, por exemplo, as regras morais, de etiqueta e meros hábitos. Estas distinções são pertinentes na medida em que permitem a definição de direito hartiana, qual seja, a de que o direito é formado a partir da união de regras primárias e secundárias.

No primeiro capítulo do livro $O$ conceito de Direito, ao tratar sobre as questões que considera persistentes para a compreensão do fenômeno jurídico, Hart afirma que três perguntas recorrentes têm sido a causa das dificuldades quanto à conceituação e a definição do conceito de "direito", sendo elas: "Como difere o direito de ordens baseadas em ameaças e como se relaciona com estas?"; "Como difere a obrigação jurídica da obrigação moral e como está relacionada com esta?"; “O que são regras e em que medida é o direito uma questão de regras?" (HART, 2011, p. $18)$.

Dentre as questões postas acima, a terceira se constitui como fundamental para o empreendimento objetivado neste artigo, pois será através dela que a discussão acerca dos diferentes tipos de regras que compõem o sistema jurídico será apresentada ${ }^{2}$. Mostraremos quais regras compõem o sistema jurídico hartiano e de que forma este se diferencia de outros comportamentos regidos por regras, por exemplo, os sistemas morais. Não obstante, argumentaremos no sentido de mostrar como alguns padrões de conduta em sociedade apresentam conformidade a condutas aparentemente regradas sem, contudo, apresentar qualquer tipo de normatividade. A saber, condutas habituais.

Por meio desta discussão pretendemos mostrar as diferenças e semelhanças normativas através das quais tanto o direito quanto a moralidade operam, salvaguardando o argumento do "conteúdo mínimo do direito", sem, contudo, negligenciar a tese da separabilidade. Para tanto, a discussão que se segue ao longo do artigo será feita a partir da obra de Herbert Hart e bem como das anotações de seus comentadores como, por exemplo, Neil MacCormick.

\section{O direito como uma questão de regras}

Ao iniciar o prefácio d'O Conceito de Direito, Hart esclarece que ao escrever sua obra não objetivava realizar uma análise conclusiva dos termos jurídicos e sim, entender o direito através do seu esclarecimento linguístico e da sua formação ${ }^{3}$. Seu objetivo não era justificar ou enumerar as possíveis aplicações práticas que podem ser feitas das normas jurídicas, mas descrever o direito, o modo como ele funciona e o que o torna possível. A partir desta conceituação é possível dizer que Hart não é normativista no sentido de que recomenda a sua teoria, mas no sentido de que concebe o direito (e não sua teoria descritiva do direito) como um sistema normativo, pautado no conteúdo das regras que o compõem ${ }^{4}$.

\footnotetext{
${ }^{2}$ As demais questões serão abordadas apenas de forma secundária, à medida que explicações e conceituações posteriores se apresentarem como demanda ao longo do texto.

${ }^{3}$ No prefácio de $O$ Conceito de Direito Hart afirma que: "muitas distinções importantes, que não são imediatamente óbvias, entre tipos de situações ou relações sociais, podem ser mais bem trazidas à luz por um exame dos usos-padrões de expressões relevantes e do modo por que estes dependem de um contexto social, ele próprio deixado frequentemente por afirmar" (HART, 2005, p. 2).

${ }^{4}$ Nesse sentido, o positivismo hartiano é apresentado como sendo um positivismo analítico normativo, uma vez que o autor não pretendia apenas descrever o direito, mas também, compreendê-lo a como uma prática normativa. O que é feito, porém, a partir do conceito de regras e não através da figura do soberano, marcando o distanciamento que faz da filosofia dos seus predecessores.
} 
É necessário separar o aspecto normativo da teoria do direito, do aspecto descritivo da teoria sobre o direito. A distinção entre o aspecto descritivo e normativo do direito é salutar, pois a má compreensão da concepção hartiana de direito deve-se, em grande parte, a desconsideração por parte de alguns teóricos da possibilidade de descrever de forma avalorativa o direito, que é uma prática normativa. Outra incompreensão da concepção hartiana está ligada a não diferenciação entre a natureza das regras jurídicas e morais.

É nesse sentido que se afirma que a teoria descritiva do direito, assim entendida, não se dirige a um sistema particular de direito, tanto menos a qualquer sistema moral. E mais, embora o direito e a moral possuam um vocabulário semelhante, é notável a distinção que existe entre essas esferas e sua forma de comando (HART, 2011, p. 11-12). O direito deve ser compreendido em termos de uma teoria geral aplicável em toda e qualquer sociedade, ao passo que a moral pode ser compreendida a partir de diferentes vieses sociais, que variam de contexto. Hart afirma que seu objetivo,

não é fornecer uma definição do direito, no sentido de uma regra por referência à qual pode ser testada a correção do uso da palavra; é antes fazer avançar a teoria jurídica, facultando uma análise melhorada da estrutura distintiva de um sistema jurídico interno e fornecendo uma melhor compreensão das semelhanças e diferenças entre o direito, a coerção e a moral, enquanto tipos de fenômenos sociais (HART, 2011, p. 22).

Ao adotar essa postura menos enrijecida acerca do direito, Hart se distancia da posição defendida pelos imperativistas, a exemplo de Austin, que segundo ele, possuíam uma visão restrita sobre a ciência jurídica ${ }^{5}$. A concepção de direito apresentada por Hart pode ser compreendida como um fenômeno social, fruto do desenvolvimento histórico das relações sociais, que se caracteriza pela oposição à ideia de que as regras operam a partir de limites fixos. Segundo MacCormick, o sistema jurídico apresentado por Hart é um "sistema de regras sociais, sociais em duplo sentido: elas tanto regem a conduta dos seres humanos em sociedade quanto devem sua origem e existência exclusivamente às práticas sociais humanas" (MACCORMICK, 2010, p. 35) ${ }^{6}$.

Assim sendo, o que é o "direito" para o autor e quais tipos de regras fazem parte da esfera jurídica e quais não são abarcadas pela teoria hartiana? Segundo Hart, o direito é formado a partir da união de regras primárias e secundárias. As regras primárias são definidas como padrões de conduta que exigem que os seres humanos pratiquem ou se abstenham de praticar certos atos impondo, dessa forma, deveres. As regras secundárias são parasitárias das primeiras e permitem introduzir novas regras, extinguir ou modificar as antigas e ainda controlar sua aplicação (HART, 2011, p. 91). Por isso podem ser compreendidas como metarregras.

As regras secundárias apresentam uma subdivisão constituindo-se em: regras de alteração, julgamento e reconhecimento. As regras de alteração conferem poder a um indivíduo ou a um grupo de indivíduos para introduzir novas regras primárias ou também para eliminar as antigas regras orientando, não obstante, o processo de extinção e estabelecimento de novas regras (HART, 2011, p. 105). Hart chama a atenção para o fato de que "é em termos de tais regras, e não em termos de ordens baseadas em ameaça, que as ideias de acto legislativo e de revogação devem ser

\footnotetext{
${ }^{5}$ Isso porque, para Austin o direito era justificado a partir das ordens do soberano, definido como aquele a quem habitualmente todo mundo obedece, mas que não tem o hábito de obedecer a ninguém. AUSTIN, John. The province of jurisprudence determined. Cambridge University Press, 1995.

${ }^{6}$ As regras sociais englobam três tipos de regras: as regras morais, as regras costumeiras e as regras do direito. Apesar de possuir um estatuto diferente, diz-se que as regras do direito também são pertencentes ao âmbito social, uma vez que o direito é compreendido como um fenômeno social, como o próprio Hart afirmou (HART, 20111, p. 22).
}

PABLOS, Mayara Roberta. A tipificação das regras e seus sentidos de obrigação. Griot : Revista de Filosofia, Amargosa - BA, v.21 n.3, p.134-147, outubro, 2021. 
compreendidas" (HART, 2011, p. 105). Fundamentando assim, a autoridade do direito por meio de critérios normativos.

As regras de julgamento determinam quais autoridades serão responsáveis por indicar e julgar e os procedimentos que os indivíduos deverão seguir. Desta forma, "além de identificar os indivíduos que devem julgar, tais regras definirão também o processo a seguir", isto é, o rito processual (HART, 2011, p. 106). A terceira e última regra é mais complexa do que as demais, pois forma a base do sistema jurídico apresentado por Hart. A regra de reconhecimento certifica quais regras fazem parte do direito e, portanto, é o critério definitório do modelo jurídico hartiano.

Dada a importância de tal regra, a pergunta que se coloca é: no que consiste tal norma e quais são as características que as define? $O$ autor salienta que embora a regra de reconhecimento não seja explicitamente declarada sua existência manifesta-se na forma como as normas concretas são identificadas, seja pelos tribunais, autoridades, indivíduos particulares ou seus advogados e assessores jurídicos. Portanto, esta regra deve ser efetivamente aceita como norteadora dos padrões públicos de comportamento oficial por parte das autoridades do sistema (HART, 2011, p. 113).

Uma regra só é dita de direito uma vez que tenha passado pelo crivo da regra de reconhecimento, que determina o arcabouço das regras que fazem ou não parte do direito. Este critério de validação é considerado abrangente, haja vista que as demais regras como, por exemplo, as da moralidade podem passar a compor o direito, desde que atendam a este prérequisito. Esta, porém, é uma característica contingente, pois nem as regras morais precisam ser incorporadas à esfera jurídica para que possamos falar sobre o direito. E mais, o fato de ter, alguma vez, incorporado uma regra moral ao direito não acarreta na necessidade de que sob o ponto de vista da validade jurídica o direito seja.

Apesar da ampla literatura a respeito da tese da separabilidade e o conteúdo mínimo do direito, estes conceitos constituem territórios em disputa pelos comentadores e filósofos do direito. $\mathrm{O}$ que justifica que este artigo se detenha sobre esta contenda com o intuito de esclarecer as diferenças e semelhanças entre estes dois tipos de regras sociais.

\section{Regras morais versus Regras Jurídicas}

Ao tratar sobre a relação entre a moral e o direito, Hart não apresentou uma definição metafísica sobre o que entende por moralidade, mas sim, exemplos acerca dos diferentes tipos de moralidade que são compartilhados pelas sociedades. Neil MacCormick apresenta uma passagem esclarecedora acerca da compreensão hartiana de moralidade ao compará-la com os padrões (standards), valores, seguidos pela coletividade. Para MacCormick, Hart parte da ideia de que "quaisquer regras ou standards que sejam compartilhados ou comuns em um grupo [...] devem ser considerados como standards morais". Estes Standards, segue ele afirmando,

\footnotetext{
tomados em conjunto [...] constituem uma "moral", isto é, a moral em grupo em questão (sendo o próprio grupo, em certo sentido, constituído pelos standards e sua aplicação, ou em referência a eles). Certamente "moral" nesse sentido não se apóia apenas ou exclusivamente na prescrição universal autônoma de cada agente moral agindo por si só [...] Uma moral assim caracterizada é social e não individual, e é a moral de um grupo de pessoas que vivem juntas e interagem socialmente (MACCORMICK, 2010, p. 69).
}

A noção de moralidade hartiana, portanto, emerge do convívio social entre os cidadãos e constitui, segundo MacCormick, o que Hart entende por moral positiva. Isto é, a moral aceita por todos os indivíduos de um grupo social. Esta acepção da moral social difere de um segundo tipo

PABLOS, Mayara Roberta. A tipificação das regras e seus sentidos de obrigação. Griot : Revista de Filosofia, Amargosa - BA, v.21 n.3, p.134-147, outubro, 2021. 
de moral descrita por Hart, a saber, a moral crítica. Esta distinção é apresentada em Direito, Liberdade e Moralidade ${ }^{7}$, outra importante obra hartiana, onde o autor afirma que a moral positiva é sinônima da moralidade social compartilhada pelos grupos como um modo de organizar suas vidas de forma normativa, ao passo que a moral crítica atua como um mecanismo de aprimoramento da moral positiva ${ }^{8}$.

É através da moral crítica que novos critérios morais passam a ser incorporados, alterados ou mesmo substituídos por outros ao longo do tempo. Estes aspectos tornam clara a importância da moralidade para a forma como os cidadãos organizam as suas vidas, de acordo com alguns padrões que devem ser aceitos pela maioria.

Esclarecido isto e tendo afirmado que há uma distinção entre o aspecto descritivo e normativo do direito e mais, que no que diz respeito ao aspecto descritivo o direito se constitui como um sistema avalorativo, insta analisar o que diferencia, em tese, o aspecto normativo das regras jurídicas e o aspecto normativo das regras de moralidade. Para diferenciar as regras morais e as jurídicas Hart elenca algumas características que delimitam de forma clara suas dessemelhanças.

A primeira característica apresentada é a da importância. De acordo com o autor, as regras morais possuem o estatuto da importância para a manutenção do convívio pacífico entre os cidadãos destacando-se, assim, dos demais tipos de regras sociais. Tal importância é apoiada pela pressão social fortemente exercida por parte da sociedade para que tais regras sejam seguidas. A pressão para o cumprimento de regras morais tem como justificativa a ideia de que qualquer alteração ou descumprimento destas regras podem resultar em consequências desagradáveis para todos os membros da sociedade. O que justifica a pressão para a não transgressão da moralidade (HART, 2011, p. 189). Oposto a isto, as regras jurídicas independem da importância, pois,

\begin{abstract}
uma regra jurídica pode ser considerada pelas pessoas em geral como não tendo importância suficiente para ser mantida; pode até haver concordância geral em como deveria ser revogada: porém, permanece como regra jurídica até ser revogada. Por outro lado, seria absurdo conceber uma regra como fazendo parte da moral de uma sociedade, mesmo que ninguém a considerasse importante ou que valesse a pena manter (HART, 2011, p. 190).
\end{abstract}

A segunda característica levada em conta para a distinção entre regras morais e jurídicas, e que decorre da primeira, é a da imunidade à alteração deliberada. As regras morais são resultado da ação do tempo, das adaptações e dos comportamentos compartilhados ao longo do tempo e, por isso, não podem ser tomadas como fruto de um ato volitivo. Não se elimina uma regra moral ou qualquer tradição compartilhada por meio de decretos ou de ato intencional que determine nulidade, já uma regra jurídica sim. Basta para tanto, um ato legislativo para que uma norma jurídica seja alterada e mesmo revogada do ordenamento jurídico (HART, 2011, p. 191). As regras do direito podem ser criadas ou revogadas do dia para a noite, prescindindo de experiências sociais de longa data.

A terceira característica é a do caráter voluntário dos delitos morais e diz respeito ao fato de a inobservância das regras morais resultarem em atos de censura quando o sujeito poderia ter agido de forma contrária ao modo como agiu, mas não o fez. Neste caso o indivíduo é censurado,

\footnotetext{
7 HART, H. L. A. Direito, Liberdade, Moralidade. Porto Alegre: Sergio Antonio Fabris, 1987.

8 Ainda segundo MacCormick, "a moral crítica é um refinamento, um desenvolvimento maior da moral positiva. Ela coloca sob reflexão crítica as nossas maneiras de julgar o comportamento e os standards - talvez meramente tradicionais - que usamos ao fazê-lo. A moral crítica busca exigir e desnudar as suposições de valores implícitos na moral positiva, reavaliá-las e torná-las coerentes e, assim desenvolver princípios críticos em referência aos quais podemos reavaliar e reorientar nossos julgamentos e normas de julgamento comuns e rotineiros (MACCORMICK, 2010, p. 73).
} 
pois poderia agir de forma moral, mas escolheu agir de outra forma. De igual modo, não parece plausível julgar moralmente ou censurar alguém que agiu mal, porém, de forma não-intencional, uma vez que se sabe que ele não poderia ter agido de outra forma naquele contexto específico ${ }^{9}$. No direito o mesmo não ocorre, pois há gradações para a determinação do delito, como o dolo ou a culpa. Assim, tomando como exemplo o direito brasileiro, ainda que juridicamente o sujeito que agiu em legítima defesa não seja julgado por uma ação dolosa, ele poderá responder por ação culposa (HART, 2011, p. 193) ${ }^{10}$.

A quarta e última característica é a da forma de pressão moral, que como o próprio nome sugere, consiste na pressão exercida pela culpa, remorso e exclusão usados pela pressão social. No que diz respeito à moral, "a forma típica de pressão consiste em apelos ao respeito pelas regras..." (HART, 2011, p.195). Este apelo ao respeito implicado nas regras morais constitui uma prática compartilhada entre os sujeitos, de tal forma que a ação moral é exercida não por ameaças ou medo, mas pela "lembrança da natureza moral da acção encarada e das exigências da moral". Assim sendo, é possível afirmar que os "apelos à consciência e a confiança no funcionamento da culpa e do remorso são as formas características e mais salientes da pressão usada para apoiar a moral social" (HART, 2011, p. 195).

No direito, a forma de pressão social exercida sobre os sujeitos fica a cargo do aspecto normativo das regras jurídicas que podem ou não vir acompanhadas de sanção. Necessário se faz esclarecer que, ainda que se aceite que a força seja característica dos sistemas jurídicos, Hart nega toda leitura acerca do direito que o caracterize e o identifique apenas pelo critério da força ${ }^{11}$. Portanto, embora o direito tenha o poder de exercer uma obrigação física, esta não é a sua única e principal característica.

O aspecto normativo é o sentido de obrigação característico do direito, por meio do qual deve ser compreendido. A obrigação normativa gerada pelo direito é fundamentada pelo conteúdo da regra e não pela força. Na prática, o sistema jurídico é cumprido quando há a compreensão de que o que a regra ordena é norma, de tal forma que esta diretriz é interiorizada e cumprida. Igualmente, age contrário ao direito aquele que não atua de acordo com o conteúdo normativo expresso pelas regras do direito ${ }^{12}$.

Tanto a moral quanto o direito exercem um tipo de pressão social para seu cumprimento, porém, há uma distinção quanto a justificativa desta pressão, que consiste no fato de que o direito é formado a partir de um sistema de regras primárias e secundárias que o configuram e conferem caráter normativo. Resulta desta distinção, além disso, o fato de que enquanto no direito a correção é feita de forma oficial, na moral o mesmo não ocorre. Uma das explicações para tanto é a de que existe apenas um direito vigente nas sociedades, por isso é considerado oficial. Ao passo

\footnotetext{
${ }_{9}$ Um caso exemplo poderia ser o de um gerente de banco que abre o cofre para o assaltante que o mantém sob a mira de um revólver. Em uma situação normal ninguém afirmaria que o gerente estaria desculpado por fornecer a senha do cofre, mas durante um assalto sim, pois parte-se do pressuposto que diante da ameaça de morte o gerente estaria justificado em tentar salvar sua vida ao fornecer a senha.

10 Não parece ser o caso de condenar moralmente alguém que agiu em legítima defesa, mas, tão somente, juridicamente. Antes, a moral diante de tal situação parece estar a serviço da isenção de culpa por parte de quem agiu em legítima defesa, ao justificar o modo como quem age desta forma o faz, uma vez que se encontra em uma situação extrema.

11 A definição do modelo jurídico hartiano tem como fundamento a ideia de que nem todas as regras jurídicas são caracterizadas por sanção, a exemplo das regras de alteração.

12 Notório é o fato de que aquele que transgride o direito pode fazê-lo tendo ele interiorizado ou não a regra jurídica. Não é preciso ter interiorizado o direito para só então, descumpri-lo. $O$ direito pode ser descumprido tanto por aquele que o toma a partir da perspectiva interna como da externa. Pense, por exemplo, nos casos em que o transgressor compreende o sistema jurídico de um ponto de vista interno, porém, não concorda com o conteúdo expresso pela regra e, por isso, age contrário a norma jurídica.
} 
que a mesma sociedade pode acomodar diferentes sistemas morais coexistentes, ainda que sejam concorrentes ${ }^{13}$.

Outro ponto a ser esclarecido é que para Hart, muito embora haja quem siga as regras unicamente por medo da pena que poderá vir a sofrer, no geral, as pessoas desejam viver em harmonia dentro de um sistema, tendo seus direitos protegidos e assegurados. E é justamente por isso que o caráter normativo advindo das regras é aceito como padrão de obrigação. Este fato explica a razão pela qual as pessoas tomam o direito a partir de um ponto de vista interno, observando o sentido de obrigação normativa proveniente das suas regras.

$O$ fato é que como temos um cenário onde as regras jurídicas são definidas como regras sociais e essas, "pertencem a uma classe geral à qual também pertencem outros tipos diversos de regra, como regras de moral, de maneiras e etiqueta, de jogos, da fala etc.", é preciso empreender mais alguns esforços na sua diferenciação frente às demais regras sociais. O que é feito a partir da compreensão de que "tal como as regras morais, as regras jurídicas também compõem a classe e “referem a 'obrigações' ou 'deveres', isto é, tornam certas condutas 'obrigatórias' ou "vinculantes". Ou seja, as regras morais também "representam um tipo de razão "peremptória" para a ação" (MACCORMICK, 2010, p. 35). Este aspecto, todavia, apenas permite distinguir o direito dos demais tipos de regras sociais, porém, não o distingue da moral.

Evidencia-se deste modo que Hart não nega a existência de alguns pontos tangenciais entre as esferas moral e jurídica, conforme apresentado no nono capítulo de $\boldsymbol{O}$ Conceito de Direito. Talvez a semelhança mais aparente desta tangência seja a que reforça a importância das "regras de conduta que qualquer organização social deve conter, para ser viável", isto é, para que possa existir. Segundo o jurista, "tais regras constituem de facto um elemento comum no direito e na moral convencional de todas as sociedades até ao ponto em que ambos são distinguidos como formas diferentes de controlo social" (HART, 2011, p. 209).

O elemento comum apresentado acima constitui o conteúdo mínimo do direito, definição a partir da qual Hart mostra como conteúdos morais que exercerem um tipo de pressão social se assemelham ao direito e a ele podem ser incorporados. Isto se torna possível na medida em que as regras morais são positivadas, passando a compor o ordenamento jurídico. É nesse sentido que se afirma que uma regra moral pode vir a se tornar uma regra do sistema jurídico, desde que esta seja devidamente validada pela regra de reconhecimento (HART, 2011, p. 312).

Deste modo, uma vez que a regra moral é positivada ela se torna parte do sistema jurídico deixando de pertencer apenas ao âmbito da moralidade, ou seja, tem seu status elevado ao deixar de ser considerada uma regra moral para se tornar uma regra do direito, onde a partir de então é tomada com pretensões não valorativas ${ }^{14}$. Um bom arquétipo acerca desta mudança de status é, por exemplo, a legislação que versa acerca do adultério ${ }^{15}$.

\footnotetext{
13 A respeito da tese da separabilidade entre direito e moral, tendo em vista o argumento do pluralismo moral e, portanto, a impossibilidade de estabelecê-la como um critério normativo lado a lado com o direito, Dimoulis faz uma distinção clara entre posições radicais e moderadas que sustentam o argumento do relativismo moral. Do lado radical da tese da separabilidade ele aloca Kelsen, que "afirma ser impossível constatar a vinculação necessária entre o direito e a moral, pois a moral é incerta, mutável e, em última análise, depende de referências puramente subjetivas", o que levanta a questão de como é possível "fazer depender o conteúdo do direito de crenças e práticas subjetivas, se a principal finalidade do ordenamento jurídico é estabelecer normas de conduta e de sanção taxativas e geralmente vinculantes?" (DIMOULIS, 2006, p. 185). A postura mais moderada fica a cargo das observações de MacCormick, que segundo Dimoulis, "não chega a afirmar que a moral é totalmente subjetiva, mas observa que as avaliações morais são mais controvertidas e incertas do que a identificação do conteúdo das normas jurídicas válidas" (DIMOULIS, 2006, p.186).

${ }^{14}$ Conforme já apresentado, a diferença substancial entre o sistema moral e o jurídico tem por base o fato de que enquanto a moral se caracteriza como um sistema de valores, o direito dever ser tomado como um sistema normativo, porém, sem a pretensão de emitir juízos valorativos no que concerne aos conceitos de "bom" e "mal" etc.

$15 \mathrm{O}$ adultério sempre foi considerado uma prática imoral, até o ponto de se tornar parte dos códigos penais de muitos países e povos. No Brasil o adultério também chegou a ser capitulado como crime no artigo 240 do código penal brasileiro. Porém, esta lei
}

PABLOS, Mayara Roberta. A tipificação das regras e seus sentidos de obrigação. Griot : Revista de Filosofia, Amargosa - BA, v.21 n.3, p.134-147, outubro, 2021. 
Hart também fala das semelhanças entre direito e moral no capítulo que antecede a seção intitulada "Direito e Moral", ao afirmar que as regras do direito e da moral,

\begin{abstract}
são semelhantes na medida em que são concebidas como vinculativas, independentemente do consentimento do indivíduo e são sustentadas por uma pressão social séria para a sua observância; o cumprimento das obrigações, quer jurídicas, quer morais, é encarado não como motivo de elogio, mas como um contributo mínimo para a vida social que é tomado como coisa corrente (HART, 2011, p. 187).
\end{abstract}

Resulta como consequência desta semelhança o fato de que "em qualquer comunidade há uma sobreposição parcial de conteúdo entre a obrigação moral e a obrigação jurídica" (HART, 2011, p. 185). O direito assim entendido faz parte de um fenômeno jurídico social, na qual está implicada a ideia de cooperação entre as partes. Esta visão do sistema jurídico é amplamente aceita e subscrita por alguns teóricos hartianos, a exemplo de Green para quem, "Hart é bem conhecido como alguém que tem uma visão social do direito, na verdade, ele acha que o direito é totalmente uma construção social" (GREEN, 2013, p. 184) ${ }^{16}$.

Se ambas exercem um tipo de pressão social e encorajam o seu cumprimento, no que consiste a diferença entre ambas? No fato de que "diferentemente das regras morais, elas [as regras jurídicas] têm uma qualidade sistemática que depende da inter-relação de dois tipos de regras, as "regras primárias" e as "regras secundárias", como Hart as chamava" (MACCORMICK, 2010, p. 35). Introduz-se aqui o sistema hartiano de regras.

$O$ direito não depende da aceitação ou não da maior parte de pessoas envolvidas para garantir sua manutenção e estabilidade. Conforme visto, podemos não aceitar uma regra. Este fato, contudo, não descaracteriza o direito enquanto tal. Dado o fato de que o sistema jurídico é normativo e impõe obrigações, as quais não estão em cogitação pelos indivíduos, pode-se dizer com propriedade que a característica do direito é, entre outras, a de estabelecer obrigações. Estas são feitas através de suas regras e do conteúdo normativo que possuem.

Assim, é possível que alguém se recuse a agir de acordo com o que uma regra social costumeira ou moral ordena, podendo sofrer ou não retaliação social, contudo, este não é o caso quando se está diante de regras jurídicas. Não é possível simplesmente se eximir de cumprir uma determinação proferida pelo juiz, sem que isso implique em uma pena correspondente, por exemplo ${ }^{17}$. Apesar disso, ao estabelecer esta característica como peculiar aos sistemas de direito, Hart não está a propor que todas as regras sejam do tipo que estabelece obrigações. Há exceções quanto ao caráter de obrigatoriedade das regras jurídicas como, por exemplo, as regras que atuam como mecanismos de alteração, entre outras.

Tendo esclarecido a diferença entre as regras sociais do tipo moral e as regras jurídicas, resta ainda discorrer sobre a distinção entre regras sociais e hábitos. Esta diferenciação é importante, na medida em que permite lançar luz para as diferentes regras sociais mencionadas de meros hábitos rotineiros, que possuem aparência de regra social do tipo moral. Faremos isso

\footnotetext{
foi revogada em 2005. Embora nos dias atuais não seja mais considerado um crime, o direito ainda legisla sobre o adultério no âmbito do direito civil quando versa sobre os deveres de fidelidade recíproca dos cônjuges conforme os artigos 1.566 e 1.704 (sobre a pensão alimentícia) do código civil. Já no âmbito da moral, o adultério ainda é amplamente criticado pela maior parcela da sociedade, que o considera uma prática que atenta contra a moral e os bons costumes.

16 Tradução nossa.

${ }^{17}$ Segundo Hart, no caso de regras jurídicas, a consequência previsível é definida e organizada de forma oficial, enquanto que no caso não jurídico seja provável uma reação hostil semelhante ao desvio, esta não é organizada, nem definida em substância (HART, 2011, p. 15). Por isso diz-se que as características da pressão social no direito e na moral semelhantes e não idênticas.
}

PABLOS, Mayara Roberta. A tipificação das regras e seus sentidos de obrigação. Griot : Revista de Filosofia, Amargosa - BA, v.21 n.3, p.134-147, outubro, 2021. 
através da noção apresentada por meio dos conceitos de "aspecto interno" e "aspecto externo" das regras, fundamental para a compreensão das regras jurídicas e do sistema proposto por Hart.

\section{Regras sociais versus hábitos}

No capítulo IV de $O$ Conceito de Direito, ao tratar sobre a noção de direito baseada nas ordens do soberano, Hart versa sobre as regras sociais e hábitos. Para o autor, existem alguns tipos de comportamentos que embora não sejam ditados por regras sociais assemelham-se a estas, como no caso de práticas habituais. A semelhança entre a prática de seguir regras e os hábitos tem como pressuposto o fato de tais comportamentos serem gerais e repetidos, o que levou Hart a analisar em que, de fato, difere um comportamento pautado em regras de outro meramente habitual.

De acordo com ele, ainda que exista semelhanças entre as regras sociais e os hábitos, três diferenças básicas podem ser elencadas para diferenciar tais categorias. A primeira é a que os hábitos são aprendidos e repassados sem que seu cumprimento tenha como pano de fundo o critério da normatividade, pois esta característica se faz ausente nas práticas habituais. Em outras palavras, basta que um grupo tenha uma ação convergente para que se estabeleça um hábito.

A segunda característica diz respeito à crítica ao desvio de padrão. As ações derivadas de hábitos não geram punição ou repressão apoiada por meio da pressão social. No que diz respeito à distinção apresentada por Hart entre hábitos e a prática de seguir regras, Noel Struchiner faz uma clara explanação sobre o tema. De acordo com Struchiner, "alguém pode ter o hábito de comer mingau três vezes ao dia, mas isso não significa que existe uma regra segundo a qual todos devem comer mingau três vezes ao dia". Desta forma, ninguém pode afirmar que alguém comete um erro ao deixar de comer mingau. Isto porque, trata-se de um hábito. "Por outro lado, quando alguém pára no sinal vermelho, normalmente isso ocorre porque internalizou uma regra segundo a qual as pessoas, incluindo a mesma, devem parar no sinal vermelho". Do que se conclui que se a própria pessoa não para diante do semáforo com a luz vermelha "é bem possível que diga mais tarde que cometeu um erro, e se as outras pessoas não param, provavelmente serão criticadas por não respeitarem a regra que determina parar no sinal" (STRUCHINER, 2005, p. 63).

Ninguém é punido pelo hábito de comer mingau, muito embora o seja por não respeitar a sinalização de trânsito. Os hábitos não figuram como critério normativo para orientação de conduta, ao passo que as regras sim. E "por isso, dizemos que censuramos ou castigamos um homem porque violou a regra e não meramente que era possível que o censuraríamos ou castigaríamos" (HART, 2011, p. 15).

A expressão do conteúdo normativo das regras gera um comportamento padrão, esperado, que justifica a regularidade por nós observada e a crítica diante do desvio a este padrão. Desta forma, não é o comportamento comum que justifica a regra, mas, ao contrário, o fato de que todos os indivíduos seguem a regra de acordo com o que ela ordena é que gera um comportamento comum em um contexto específico ${ }^{18}$. Portanto, é a prática de seguir a regra de acordo com o que ela ordena que torna evidente a ordem expressa pela regra.

Como os hábitos não geram comportamento normativo comum, no sentido de que prescindem de normatividade, eles não podem figurar como parâmetro de correção no mesmo sentido que as regras jurídicas ou morais. E este é outro ponto relevante quanto à distinção entre regras e hábitos apresentado por Hart no momento em que ele trata sobre as questões recorrentes

${ }^{18}$ Do mesmo modo, a transgressão das regras gera um comportamento oposto ao esperado frente ao padrão normativo, o que justifica a censura.

PABLOS, Mayara Roberta. A tipificação das regras e seus sentidos de obrigação. Griot : Revista de Filosofia, Amargosa - BA, v.21 n.3, p.134-147, outubro, 2021. 
no direito, mais especificamente sobre as críticas ao modelo imperativo do direito. De acordo com ele, o direito não pode ser compreendido pela mera ideia de hábitos e ações convergentes, justamente porque falta a estas práticas o aspecto institucional e normativo que o direito reivindica. Por isso "esta distinção é crucial para a compreensão do direito" (HART, 2011, p. 16).

Se seguíssemos uma regra jurídica meramente pelo hábito de assim o fazer a ocorrência de mudança de hábito, por menor que fosse, caracterizaria um novo comportamento e, necessariamente, um novo direito. Neste sentido, seria o hábito que moldaria o direito e sua necessidade e não o oposto, como se está a defender. O que se percebe, contudo, é que nossos hábitos podem ser alterados, mas disso não se segue como necessário que o direito também o seja. Além disso, o modo como os hábitos são revogados, por cair em desuso, difere totalmente do modo como as leis jurídicas são revogadas, através de atos institucionais.

A terceira característica diz respeito ao aspecto interno das regras e é apresentado por Hart através da afirmação de que para que haja qualquer hábito "não se exige que nenhum dos membros do grupo pense, de qualquer modo, no comportamento geral ou saiba sequer que o comportamento em questão é geral". Ou seja, "basta que cada um, por seu lado, se comporte da forma que os outros também se comportam efectivamente" 19 . Ao passo que "para que uma regra social exista, alguns membros, pelo menos, devem ver no comportamento em questão um padrão geral a ser observado pelo grupo como um todo". A conclusão à qual Hart chega é a de que "uma regra social tem um aspecto 'interno', para além do aspecto externo que compartilha com o hábito social e que consiste no comportamento regular e uniforme", passível de ser observado e registrado por qualquer indivíduo (HART, 2011, p. 65).

A distinção entre o que chamou de aspecto "interno" e "externo" das regras além de delimitar as diferenças entre hábitos e a prática de seguir regras, também elucida a diferença entre a prática de seguir a regra da mera ação conforme a regra, ou seja, sem atitude crítica reflexiva (HART, 2011, p. 66). A definição sobre os aspectos "interno" e "externo" das regras é dada por Hart através da seguinte citação:

quando um grupo social tem certas regras de conduta, este facto confere uma oportunidade a muitos tipos de asserção intimamente relacionados, embora diferentes; porque é possível estar preocupado com as regras, quer apenas como um observador, que as não aceita ele próprio, quer como membro de um grupo que as aceita e usa como guias de conduta. Podemos chamar-lhes os 'pontos de vista' respectivamente 'externo' e “interno” (HART, 2011, p. 98-99).

Ao tratar sobre o ponto de vista externo do direito Hart o subdivide em (a) ponto de vista radicalmente externo e $(\mathrm{b})$ ponto de vista externo engajado. $\mathrm{O}$ primeiro aspecto diz respeito à apreensão das práticas em uma dada comunidade a partir da observação de suas condutas, sem que o próprio observador interiorize o conteúdo normativo das regras. Por isso se diz que o ponto de vista radicalmente externo é descritivo, uma vez que quem observa descreve o modo como os indivíduos agem, sem saber as razões que levam tais sujeitos a agir de determinado modo. Ou seja, a análise feita do ponto de vista externo limita-se a descrever os comportamentos regulares observados, pois não toma em consideração o conteúdo das regras que coordenam as respectivas práticas. Este é o caso, por exemplo, do observador radicalmente externo que apenas descreve as práticas e regularidades observadas em uma comunidade, porém, não as compreende.

A segunda tipificação do aspecto externo pode ser explicada através da imagem do observador engajado que leva em consideração o que as regras dizem, mas não as aceita ele

\footnotetext{
19 Ainda que os hábitos observados pudessem encorajar práticas, estas seriam realizadas apenas enquanto comportamento de massa e não como uma atitude normativa guiada por regras.
}

PABLOS, Mayara Roberta. A tipificação das regras e seus sentidos de obrigação. Griot : Revista de Filosofia, Amargosa - BA, v.21 n.3, p.134-147, outubro, 2021. 
próprio. Segundo Hart, este observador "pode, sem ele próprio aceitar as regras, afirmar que o grupo aceita as regras e pode assim referir-se do exterior ao modo pelo qual eles estão afectados por elas" a partir do ponto de vista interno (HART, 2011, p. 99). Neste caso o observador compreende o padrão normativo seguido, porém, não aceita o aceita, por isso, limita-se apenas a descrever o padrão interno das ações de outros indivíduos sem que isto seja feito a partir do seu próprio ponto de vista interno.

O ponto de vista interno, ao contrário, tem como fundamento o conteúdo normativo das regras que são seguidas por determinados indivíduos como justificação para o modo como suas ações são executadas. Desta forma, o ponto de vista interno possui uma linguagem normativa, não sendo meramente descritiva como o externo. $O$ aspecto interno pressupõe uma atividade crítica e reflexiva acerca das práticas realizadas, entendida como um padrão a ser seguido. Conhecer o ponto de vista interno implica em conhecer as razões que motivam as ações e seu caráter normativo e, portanto, “compreender o direito passa a ser, necessariamente, compreender o seu caráter institucional, o que demanda um ponto de vista 'interno' na compreensão do seu sentido" (KOZICKI, 2014, p. 58).

Através das definições sobre o aspecto interno e externo das regras Hart pretende esclarecer a distinção que há entre um hábito estabelecido na sociedade como, por exemplo, tirar o chapéu ao entrar na igreja e uma regra jurídica, como a prática de parar no sinal vermelho do trânsito. Seu objetivo é mostrar de que modo as ações habituais observadas na sociedade diferem das demais regras, sobretudo as do direito, o que é feito através da relação entre o aspecto interno das regras e seu conteúdo normativo.

É preciso ter em conta, que o aspecto externo das regras também pode ser entendido de forma normativa, como no caso do indivíduo que compreende o ponto de vista interno, mas não o aceita e, portanto, assume a postura de observador externo. A partir deste argumento Hart reitera sua tese de que a diferença entre o aspecto interno e externo das regras não é a ausência de normatividade, mas sim, uma atitude postural diante do conteúdo da regra. $\mathrm{O}$ fato de que os sujeitos não aceitam o critério expresso pela regra como parâmetro para suas ações não implica, portanto, a inexistência de normatividade. Trata-se apenas da recusa a este padrão.

Ainda sobre o aspecto externo das regras um último esclarecimento deve ser feito. Alguns críticos da teoria de direito hartiana poderiam questionar o alcance do argumento do aspecto radicalmente externo. Isso porque, embora Hart tenha afirmado que um observador possa permanecer apenas no aspecto radicalmente externo das regras ao descrevê-las com certo êxito ao fazê-lo, entretanto, o observador não consegue classificar com certeza quais regras são parte ou não do sistema jurídico. A menos que o observador faça parte do sistema em questão.

Neste caso, ele está inserido dentro da sociedade e sob a égide das regras que coordenam e legislam a comunidade. Em última instância, não seria possível saber distinguir as ações, uma vez que o observador não compartilha dos padrões seguidos, tampouco, está inserido na prática de seguir regras naquela sociedade em específico. Somente quando o indivíduo compartilha do modo de vida, das práticas de uma sociedade e sistema jurídico é que se torna possível distinguir entre hábitos e regras. Igualmente, somente então a ele é facultado agir a partir do aspecto externo engajado ou interno das regras, segundo suas motivações ${ }^{20}$.

Em outras palavras, a escolha entre agir de acordo com o aspecto interno do direito, observando as regras e as aceitando como critério normativo de condutas ou agir a partir de um

\footnotetext{
${ }^{20}$ Uma segunda questão levantada é a de como saber se um indivíduo agiu de acordo com o ponto de vista interno ou externo e que importância isso teria para o cumprimento do direito. Porém esta discussão está além dos limites deste trabalho.
} 
ponto de vista externo, sem aceitar as regras, tendo sua ação conforme ao direito apenas por medo da punição, se torna possível apenas uma vez tendo conhecido o aspecto interno. Somente após compreender o conteúdo normativo da regra é que a possibilidade se coloca para o indivíduo, a ele é facultado escolher.

Um observador radicalmente externo, que não conhece o modo como uma sociedade é coordenada não pode distinguir entre regras, costumes e hábitos, sem antes fazer parte destas práticas ou conhecê-las. Se o que Hart está a defender, como parece ser o caso, é que é possível que o observador radical externo descreva com certo grau de êxito as condutas e o que levou os agentes a realizá-las, inclusive prevendo as possíveis sanções que podem ser infligidas, ele incorre em um erro argumentativo. Em que consiste esse erro?

Hart diz que o observador no começo contenta-se apenas com as anotações das regularidades dos comportamentos observados e que estas regularidades "consistem em parte a conformidade com as regras, e das demais regularidades, na forma de reacções hostis, censuras e castigos com que os desvios das regras são combatidos" (HART, 2011, p. 99). E mais, que depois de algum tempo o observador externo pode, "com base nas regularidades observadas, correlacionar os desvios com as reações hostis", tornando-se "apto a predizer com uma razoável medida de êxito e avaliar as probabilidades com que um desvio do comportamento normal do grupo será enfrentado com uma reacção hostil ou castigo" (HART, 2011, p. 99).

O problema é que só é possível saber que alguém cometeu um erro quando conheço a regra e o que seu conteúdo expressa. Somente então sei que alguém agiu de forma contrária a ela. Segundo que para poder prever com algum êxito as reações hostis que certo comportamento desviante irá sofrer também é necessário saber que tipo de erro foi cometido, qual regra foi transgredida. É necessário compreender ainda quais regras são seguidas para aplicar a punição, pois somente assim o observador poderia elencar um rol de comportamentos hostis que resultariam em castigo para o transgressor.

Note a quantidade de conteúdos normativos que é preciso ter em conta para que seja possível prever a transgressão às regras e os castigos relativos a este ato. É preciso saber o conteúdo da regra para somente depois saber se ela foi violada e poder punir comportamentos desviantes, pois só assim será possível saber que esta punição está sendo aplicada por conta deste contexto específico e não de outro.

Adotar um ponto de vista radical externo é totalmente diferente de adotar um ponto de vista externo, porém, engajado. Diferença esta que consiste no fato de que o observador externo engajado conhece as regras jurídicas e seu conteúdo, mas resolve não aceitá-las. Isso porque, este observador, antes de tudo, compreendeu o conteúdo da regra para só depois, então, colocar-se na postura externa. Além disso, há a possibilidade de conhecendo o conteúdo da regra o espectador agir segundo sua prescrição somente para evitar qualquer sanção jurídica, sem, contudo, dar seu assentimento para o seu conteúdo (HART, 2011, p. 99).

Dizer que tal compreensão só é possível quando estamos inseridos nas práticas da comunidade não implica em subscrever a tese comunitarista das regras de que o que permite distinguir entre uma regra e outra é a prática social. Se tal compreensão se baseasse apenas no comportamento comunitário cairíamos no problema de ter que assumir que o comportamento comum justifica a regra e não o contrário. Ou ainda, que o aspecto externo é suficiente para fundamentar uma prática. Esta compreensão, no entanto, é oposta à noção hartiana de regras e normatividade e o que neste artigo se defende.

Portanto, a normatividade é dada sempre pela regra que gera um comportamento comum, cujo caráter é o de uniformidade das ações dos indivíduos gerada a partir do conteúdo normativo seguido. Este, portanto, pode ser analisado tanto a partir de uma postura externa engajada,

PABLOS, Mayara Roberta. A tipificação das regras e seus sentidos de obrigação. Griot : Revista de Filosofia, Amargosa - BA, v.21 n.3, p.134-147, outubro, 2021. 
quanto de uma postura interna, isto é, crítica reflexiva acerca do uso das regras. Somente a partir da perspectiva interna é que podemos distinguir entre regras jurídicas, morais e os hábitos que partilhamos na sociedade na qual estamos inseridos. Isso porque conhecemos os diferentes tipos de regras e os elementos que configuram seus conteúdos e seu caráter normativo. Compartilhamos a mesma forma de organizar nossas atividades.

\section{Conclusão}

Frente ao exposto, conclui-se que o direito é uma construção social cujas regras não são morais, nem meros hábitos, muito embora regras morais e costumeiras possam vir a compor o direito quando da sua positivação a partir da incorporação destas ao mesmo, por meio da regra de reconhecimento. Ainda que Hart conceda que há uma sobreposição de conteúdos morais sobre a esfera jurídica, ele nega que a conceituação do direito seja dependente de quaisquer conteúdos morais.

Embora haja semelhanças nas práticas de seguir regras sociais como o direito e a moral, cada esfera possui sua especificidade de forma independente. Hart é taxativo ao afirmar que um sistema de direitos é independente de qualquer valoração moral. O que permite distinguir o aspecto descritivo da teoria jurídica do aspecto normativo, que é característico do direito e suas regras.

Foi mostrado também que o caráter normativo do direito advém do conteúdo das suas regras e não de uma postura habitual, como a de seguir as ordens expressas por um soberano como outrora havia sido defendido por posturas imperativistas. Além disso, esclarecemos que os hábitos não possuem força normativa e, por isso, o não cumprimento de um hábito não é passível de qualquer imputação ou repressão por parte dos demais indivíduos. Somente as regras veiculam critérios normativos que determinam e orientam as ações e por isso se diz que elas são, ao mesmo tempo, o critério de conduta para ação e para correção das ações.

O sistema jurídico assim entendido, está pautado em critérios normativos oriundos da sua própria estrutura - regras primárias e secundárias -, por meio das quais é possível distinguir as regras jurídicas das demais regras sociais e os hábitos. Por fim, também foi demonstrado que apesar de possuir como característica o fato de determinar ações, o direito como união de regras não tem como pressuposto unicamente a coerção. O que foi feito através do argumento de que nem todas as regras do direito resultam em sanções ${ }^{21}$.

\footnotetext{
${ }^{21}$ Ainda segundo Hart: "De facto, penso que é totalmente despiciendo procurar qualquer finalidade mais específica que o direito enquanto tal, sirva, para além de fornecer orientações à conduta humana e padrões de crítica de tal conduta. Isto não serviria, claro, para distinguir as leis de outras regras ou princípios com os mesmos objetivos gerais; os aspectos distintivos do direito residem na consagração que faz, através das regras secundárias, de providências para identificação, alteração e execução dos seus padrões, e na pretensão geral que adopta quanto à primazia sobre outros padrões" (HART, 2011, p. 310).
} 


\section{Referências}

AUSTIN, John. The province of jurisprudence determined. Cambridge University Press, 1995.

BIX, Brian. "On the Dividing Line Between Natural Law Theory and Legal Positivism", Notre Dame Law Review, Vol. 75. 2000.

CAMPBELL, Tom. Re riting Hart's Postscript: Thoughts on the Development of Legal Positivism. Problema. Anuario de Filosofia y Teoria del Derecho. N. 5. Universidad Nacional Autónoma de México: 2011;

DALL'AGNOL, Darlei. Seguir regras: uma introdução às Investigações Filosóficas de Wittgenstein. Pelotas: Ed. Da UPel, 2011.

DIMOULIS, D. Positivismo Jurídico: introdução a uma teoria do direito e defesa do pragmatismo jurídico-político. São Paulo: Método, 2006.

GREEN, L. The Morality in Law. In: Reading HLA HART'S the concept of Law. Oxfor and Portland. Oregon, 2013.

HART, H. L. A. Direito, Liberdade, Moralidade. Porto Alegre: Sergio Antonio Fabris, 1987.

HART, H. L. A. Ensaios sobre teoria do direito e filosofia. Rio de Janeiro: Elsevier, 2010.

HART, H. L. A. El Nuevo Desafio del Positivismo Jurídico. In: Sistema, no 36. Madrí: Original inédito, 1980. p.3-18.

HART, H. L. A. Essays in Jurisprudence and Philosophy. Nova Iorque: Oxford University Press, 1993.

HART, H. L. A. O Conceito de Direito. Trad. A. Ribeiro Mendes. $6^{\circ}$ ed. Lisboa: Fundação Calouste Gulbenkian. 2011.

HART, H. L. A. The Concept of Law. Oxford: Clarendon Press, 1998.

KELSEN, H. Teoria pura do direito. Tradução João Baptista Machado. $6^{\text {a }}$ ed. - São Paulo: Martins Fontes, 1998.

KOZICKI, K. Herbert Hart e o positivismo jurídico: textura aberta do direito e discricionariedade judicial. Curitiba: Juruá, 2014.

MACCORMICK, N. H. L. A. Hart. Tradução Cláudia Santana Martins; revisão técnica Carla Henriete Beviláqua. - Rio de Janeiro: Elsevier, 2010.

STRUCHINER, N. Direito e Linguagem. Uma análise da textura aberta da linguagem e sua aplicação ao Direito. Rio de Janeiro: Renovar, 2001.

Autor(a) para correspondência / Corresponding author: Mayara Roberta Pablos. mayara_pablos@yahoo.com.br

PABLOS, Mayara Roberta. A tipificação das regras e seus sentidos de obrigação. Griot : Revista de Filosofia, Amargosa - BA, v.21 n.3, p.134-147, outubro, 2021. 